\title{
NEWTON'S SCHOLIUM ON TIME, SPACE, PLACE AND MOTION
}

\author{
ROBERT RYNASIEWICZ
}

\section{INTRODUCTION}

After a preface to the reader and an ode by Edmund Halley, Isaac Newton's Philosophiae naturalis principia mathematica (1687) opens with eight definitions that fix the meanings of various technical terms in dynamics. ${ }^{1}$ Newton begins with 'quantity of matter', equivalently 'mass' or 'body' [corpus]. Next, the quantity of motion of a body is the product of its velocity with the quantity of matter. The remaining six definitions pertain to the concept of force. The first two are contrastive. Vis insita is the internal capacity by means of which a body attempts to preserve its state of rest or uniform motion in a straight line, while vis impressa is an action exerted on a body to change its state. A special case is vis centripeta, namely, when bodies are drawn or impelled, or in any way strive toward some point as a center. Finally, Newton introduces three measures of vis centripeta: its absolute, its accelerative, and its motive quantities, respectively. It is not assumed that the reader has previous familiarity with any of the defined terms. There follows an ample Scholium, the opening sentence of which reads, "Thus far, it has seemed best to explain the sense in which lesser known words are to be accepted in what follows" (11, CW 408). ${ }^{2}$ The definitions thus have a stipulative character. ${ }^{3}$

Newton does not provide definitions in like manner for the fundamental kinematic quantities of time, space, place and motion. Instead, before going on to state the Laws of Motion, he addresses them in that Scholium. Since these quantities are supposedly wellknown to all, he informs the reader that he will not define them. However, since ordinary people [vulgus] understand them only in relation to perceptible things, they develop certain prejudices (a theme familiar from Descartes with which Newton was familiar). In order to dispel them, he will distinguish in each case the absolute, true and mathematical quantity from its relative, apparent and ordinary [vulgares] counterpart.

The laws of motion following the Scholium are to be understood in terms of the absolute quantities. Indeed, even such previously defined terms as quantity of motion, vis

\footnotetext{
${ }^{1}$ Unlike most, who look upon the third edition as the canonical text, I will focus on the first instead. The Scholium to the definitions is virtually the same in all three editions. My reasons for focusing on the first edition will become evident in what follows.

${ }^{2}$ All translations are mine. For the readers convenience, I also give the page numbers of the corresponding passage in the Cohen and Whitman translation of the third edition (1726), hereafter marked CW. Copies of the first edition are readily available online. In particular, Project Gutenberg has produced a searchable ebook.

3 "By 'lesser [known]' Newton does not suppose that the words themselves are not well known; rather, he means that he is using these words in and unfamiliar sense to express concepts that are new" (CW 85)
} 
insita, or vis impressa cannot be properly understood without these distinctions. They are fundamental to Newton's entire project.

The project of this essay is to review the strategy of the Scholium and to analyze the arguments Newton presents therein. ${ }^{4}$

\section{Definitions of 'Definition'}

As just mentioned, in the Scholium Newton declines to define time, space, place and motion, at least in the manner done for quantity of matter and and the various quantities of force. Nonetheless the four paragraphs of the Scholium labeled I-IV read as though they are involved in giving definitions, especially paragraphs III and IV. Paragraph III introduces 'place' [locus]: "Place is a part of space which a body occupies, and is either absolute or relative according to the space" (5-6); Paragraph IV appears to define motion [motus], both absolute and relative: "Absolute motion is the transference of a body from an absolute place to an absolute place; relative from a relative [space] to a relative [space]" (6). How is the reader to understand this?

These indeed can be called definitions if one carefully distinguishes between different types of definition. For instance, the Port Royal Logic (Arnauld and Nicole 1662) warns us not to confuse what it calls the definition of names, with the definition of things.

In the first part, we have spoken at great length about definitions of names, and we have shown that they must not be confused with definitions of things; because the definitions of names are arbitrary and incontestable, whereas the definitions of things do not depend on us, but on what is contained in the true idea of a thing; and must not be taken for principles, but are to be considered as propositions which must often be confirmed by reason, and which can be disputed. (1662, 190; 1674, 118)

The opening eight definitions labeled as such, which I referred to as stipulative definitions, fall under the Port Royal heading of definitions of names. They are neither true nor false, but set up the way certain words shall be used. In contrast, definitions of things attempt to capture what things really are, their natures or in what they consist. As such they are substantive theses, evaluable as correct or incorrect, and consequently, as the quote indicates, subject to disputation. ${ }^{5}$

A Latin translation of the Port Royal Logic (originally in French) is listed in Newton's personal library (Harrison 1978, 182, item 980). However, the publication date, 1687, makes it too late to have played a role in shaping the opening structure of the Principia, which is already worked out in the manuscript De Motu Corporum Liber Primus (Dd-946), Lucasian lectures dated by Whiteside to spring or autumn of 1685 (Whiteside 1989). It is of course possible that Newton was familiar with earlier Latin editions $(1674,1682)$ or even the English translation of 1685. We need not conjecture, though. Distinctions between different types of definition hark back to antiquity. Newton would have encountered them in his undergraduate training, e.g., from Aristotle's Organon (see McGuire and Tamny, p. 4).

\footnotetext{
${ }^{4}$ The present article extends work presented in Rynasiewicz 1995a, 1995b, and 2014.

${ }^{5}$ For a modern discussion of the full variety of types of definition, see (Gupta 2008).
} 
Isaac Barrow's Lectiones Geometricae notes that natural philosophers [Physici] argue in detail about the nature of motion and its true or proper [rectâ] definition (Barrow 1670, 1). Moreover, Newton owned a copy, with signs of dog-earing, of the third edition of Robert Sanderson's Logicae artis compendium (Sanderson 1631), described by Sgarbi (2013) as "the most important and influential seventeenth-century textbook of logic in England" (152). Chapter 17, De Definitione, introduces a contrast between the definition of names [definitio nominis] and the definition of things [definitio rei]. The latter, though couched in scholastic terms, has the same upshot as in the Port Royal Logic. The former differs slightly from its Port Royal homonym in that it is not stipulative, but instead intends to disclose the conventional usage of the term. The point, though, remains: Newton was certainly exposed to the practice of crafting real or true definitions of things, e.g., in his reading of Descartes' Principia philosophae (1644), and he would have been amply confronted with stipulative definitions in his mathematical studies, e.g., in part 3 of Huygens' Horologium oscillatorium (1673).

The very structure of the scholium turns on the distinction between stipulative and real definitions. After setting out his characterizations of the absolute quantities in contrast to the relative, Newton is concerned to defend these true definitions and to establish that the absolute quantities are ontologically distinct from their relative counterparts in that the absolute quantities are not reducible to certain instances of relative quantities. This justificatory work occupies him up to the penultimate paragraph. Some of it is done immediately upon introduction of the "true" definition, specifically in paragraph III, where he immediately defends his characterization of place against two rival definitions. Most of the justificatory work, however, is done in the eight paragraphs following I-IV. In particular, the last five of these target the distinction between true and absolute motion and rest, on the one hand, and merely relative motion and rest, on the other, based on their properties, causes and effects. The argument from effects involves the famed rotating bucket experiment. These arguments, individually and taken together, seek to show that the true motion of a body cannot be defined as any particular species of its motion relative to other bodies. The penultimate paragraph then recapitulates the general theme that the absolute quantities are indeed distinct from the relative and not reducible to them, commenting as well on whether the scriptures are to be interpreted in terms of the absolute or the relative quantities. The final, lengthy paragraph takes up a different, epistemological issue. Given that absolute space does not affect the sense organs, how is it possible to come to know the true motions of bodies in the world? Newton illustrates how this can be done, using the example of a pair of globes tethered together and revolving about their center of gravity. He promises to show more fully in what follows, how to infer [colligere] the true motions from their causes, effects and apparent differences, as well as the causes and effects from the motions, whether true or apparent. For, he says, it was to this end that he composed the treatise. Book III bears him out. 


\section{True Motion prior to Newton}

When Newton declares at the outset of the Scholium that he will distinguish between the absolute and relative, true and apparent, mathematical and common [vulgares] quantities, he intends to introduce one, not three distinctions. This is apparent at the beginning of Paragraph I, where, without pause he speaks of absolute, true and mathematical time in contrast to relative, apparent and common time. The terminology 'absolute' vs. 'relative' appears to be new with Newton. ${ }^{6}$ But 'true' vs. 'apparent' has a long history going back to antiquity, especially when predicated of motion. Before discussing the arguments of the Scholium in detail, it is worth reviewing the historical standing of the distinction at the time the Principia was drafted. For each of the arguments from properties, causes and effects presupposes that each body has a unique state of true motion or rest, where true motion and rest are held to be contradictory properties. By 'property' I mean, in the parlance of mathematical logic, that the predicates 'truly moves' and 'truly rests' are complete monadic predicates that are not elliptical for relational predicates ' $x$ moves relative to $y$ ' or ' $x$ is at rest relative to $y$ ', where $y$ is to be filled in by a coordinate chart, a frame of reference, a system of bodies, a single body, a relative space or even absolute space. In other words, 'truly moves' and 'truly rests' were held to be complete predicates.

This is familiar from antiquity. That a given body is truly at rest or moves with a unique degree of true motion was hardly controversial, whether one believed in an infinite void or in a finite cosmos in which all extension is corporeal. As a ship leaves port, it may appear that the shoreline is receding, when in fact it is the ship that is really moving, not only according to ordinary sailors, but also according to sophisticated philosophers, such as Aristotle, who rejected the existence of any background space against which true motion is to be judged. The major cosmological question hinged on the distinction between true and merely apparent motion. Does the starry sky really rotate daily about the earth, or is it the earth that actually rotates while the heavens only appear to move? Does the sun really move full circle through the zodiac each year, or is this an apparent motion due the actual revolution of the earth about a stationary sun? Aristotle, Ptolemy, Copernicus, Tycho, and Descartes inter alia, all weighed in on these questions with varying answers, yet none of them understood true motion to consist in change of place in an immobile space.

No less was the distinction between true and apparent motion taken for granted in the astronomical tradition following Copernicus, especially as it became important not just to predict the angular positions of celestial bodies, but to compute their trajectories in 3-space as a function of time. Representative is Vincent Wing, whose Harmonicon Coeleste (1651) Newton studied as an undergraduate (see McGuire and Tamny, 300). In the preface "To the Judicious Reader" Wing promises that he will show

how to calculate the true Motions of the Earth, Planets and fixed Stars, for any time past or to come by new Tables, calculated according to the

\footnotetext{
${ }^{6}$ But it may have been inspired by Barrow 1670. There, time is defined as the persistence of any thing in its being [tempus est perseverantia rei cujusque in suo esse], which, as we will see below accords with Newton's conception of absolute time. A few lines later Barrow writes, Ergo tempus absolutè quantum est ... (2).
} 
Doctrine of the third Book, whereby there $[$ sic $]$ true places from the Sun may exactly be obtein'd, .... (my emphasis)

Obtaining the true places as a function of time yields the true orbits, ${ }^{7}$ a consideration brought to the fore by Kepler. At the beginning of his Astronomia Nova (1609), he poses the convoluted character of the orbits generated by the Ptolemaic and Tychonic systems as an argument for Copernicanism. After describing the first and second inequalities and the data available for the distances from the earth to the outer planets at their oppositions and near their conjunctions, he writes:

If anyone ... were to believe that the sun truly [re vera] moves in the space of a year through the zodiac, which Ptolemy and Tycho Brahe believed, then it is necessary to concede that the paths of the three superior Planets through ethereal space, composed as they are of several motions, are in reality $[$ re vera $]$ spirals ... in the figure of a pretzel, in the general fashion that follows. (3, emphasis added)

Kepler then explicitly draws out the resulting orbit of Mars over the years 1580-1596 according to the Ptolemaic and Tychonic systems. (See Fig. 1.) Clearly, the true motions

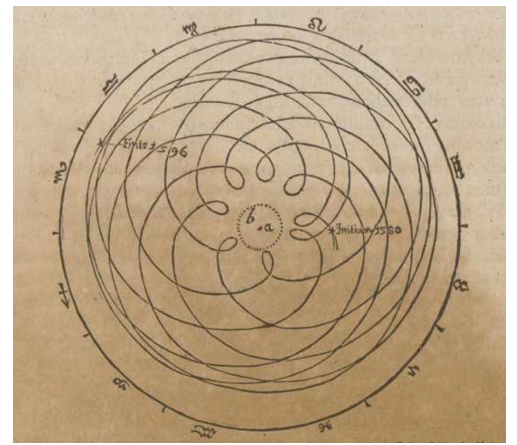

FiguRE 1. Kepler's sketch of the orbit of Mars for the years 1580-1596 according to the Ptolemaic and Tychonic systems.

yield the true orbits. Conversely, the true orbits, correctly parametrized by time, yield the true motions.

What, then, about the emerging science of dynamics? Doesn't the principle of inertia indicate that rest and motion are not contradictories, and doesn't the recognition of dynamical relativity, in response to Aristotelian arguments against a moving earth, demand the obliteration of a distinction between rest and uniform rectilinear motion?

Galileo is typically cited as the first to enunciate a principle of relativity, specifically in the Dialogo from 1632, where his spokesman, Salviati, asks his interlocutors to imagine an array of experiments done inside the hull of a ship, the results of which, he confidently proclaims, will be the same no matter whether the ship is at anchor or under sail with any

\footnotetext{
${ }^{7}$ Wing follows Kepler in taking them to be ellipses.
} 
speed you like, as long as its motion on the surface of the sea is uniform. If Salviati is right, what follows? It's crucial for Galileo that this uniform motion be along the circumference of the earth. The absence of any experimental effects of the ship's motion is supposed to defeat the Aristotelean/Ptolemaic argument to the effect that, if the earth were to rotate, then there would be observable effects, such as falling projectiles lagging behind. Galileo's counterargument is that a rotating earth is to a stationary earth as a circumnavigating ship to a stationary ship on a stationary earth: if there are no observable effects due to a ship's circumnavigation of a stationary earth, there should be no observable effects due to a diurnal rotation of the earth. The conclusion is that the hypothesis of a rotating earth yields the same observable phenomena as the hypothesis of a stationary earth, and thus the absence of any such effects does not militate against a rotating earth. However, Galileo does not conclude that there is no fact of the matter as to whether the earth rotates, any more than the nullity of the experiments fails to establish there is no fact of the matter as to whether the ship is circumnavigating a stationary earth or not. Indeed, the very purpose of the Dialogo is to argue for a moving earth. ${ }^{8}$

Far from denouncing a real distinction between true rest and motion, Galileo explicitly embraces it when Salviati proposes to account for the apparent acceleration of free fall as a frame-effect due to the compounding of two different uniform circular motions. As he says, "the true and real motion of the stone is never accelerated at all, but is always equable and uniform" (1967, 166 emphasis added). Galileo takes this true and real motion of the projectile to be a semi-circle from the top of the tower from which the stone is released to the center of the earth. The explanation is that, moving with the appropriate circular inertia so as to stay motionless with respect to the earth's surface, the observer, whose true motion is uniform along the circle surrounding the earth through the top of the tower, sees an apparently accelerating rectilinear decent toward the base of the tower. The true motion of the stone would be seen only for an observer not sharing in the true circular motion of the earth, i.e., only in an absolutely stationary frame, just as, according to Kepler, one sees the true motion of Mars only in the stationary frame of the sun.

Pierre Gassendi, credited with the first published enunciation of the law of rectilinear inertia, likewise retained the distinction between rest and true motion. Towards the end of the first of two letters to Pierre du Puy, dated 11 December 1940, which appeared in print in 1642 as De motu impresso a motore translato, he addresses the perceived difficulty that projectile motion must be sustained by some force imparted to the projectile, as required, for example, by medieval impetus theory. However, the reason for the continued motion in the projectile is not an active, but rather a "passive force":

... whenever an object is in reality [reipsa] moving, one must not look for any active force in it, which is necessary only in the mover, but only a passive force .... And the fact that the mover is separate or that it may even have perished is no hindrance to the continuation of the motion once it is transferred, for in addition to the motion the mover is not required

\footnotetext{
${ }^{8}$ The fourth day of the Dialogo argues that the tides are evidence for the combined diurnal and annual motion of the earth.
} 
to transmit any other force to maintain the motion subsequently, but it is enough if it imparts the motion once to the moving object, which can then continue without it. (Brush, 143; Gassendi 1642, 74)

Specifically, for Gassendi motion is a property with a subject.

Now [the object] is able to [continue in motion] because motion is an accident of a nature which can endure without continuous action of its cause as long as its subject continues to exist and it does not come up against something contrary to it. (Ibid.)

Of course, it is to be assumed that rest is also an accident that endures in its subject without continuous action unless something contrary to it intervenes. Significantly, Gassendi does not bring to bear his views on place (and time) on his analysis of rest and motion in $D e$ motu. Contrary to Aristotle and the scholastics and in accord with Epicurus and Lucretius, he affirmed, in addition to the corporeal extension of bodies, the existence of incorporeal extension, i.e., space distinct from body, and also of time, as entities in their own right, fitting the category of neither substance nor accident.

This contrasts with Descartes, who publicly articulated the law of rectilinear inertia shortly thereafter in his Principia philosophiae of 1644. As is well-known, for Descartes there is only one kind of extension. Whether one calls it matter or space, it continually rearranges itself, giving rise to the various forms of nature. Out of all of the relative motions of one part of extension, or body, with respect to others, Descartes nonetheless maintained that, in reality [ex rei veritate] there is a movement proper [proprius] to it, (Bk. II, Art. 31) viz., its transference from the vicinity of those bodies which are immediately contiguous and regarded as if [tanquam] they are at rest, to the vicinity of others (Bk. II, Art. 25). ${ }^{9}$ Since for each body there is but one collection of bodies immediately contiguous, the motion proper to it, as he repeatedly emphasizes, is unique (or else the body is at rest, properly speaking). This is an affirmation, by another name, of true motion, and it is with reference to true motion that he frames the law of inertia and his rules of collision. Furthermore, although his system of the world is Copernican in that the earth is swept round the sun by a vortex of subtle matter, he nonetheless preserves the Catholic orthodoxy that, truly speaking, the earth is at rest since it is not displaced from the vicinity of the immediately contiguous subtle matter.

It can be misleading to say, as did René Dugas, that Descartes had "a purely relativistic conception of motion" $(1958,172)$ or to assert, as did Sam Westfall, that he maintained "the relative nature of motion" $(1971,58)$. For this suggests that Descartes held that all of the many relative motions of a body has with respect others are on a par, as though he hadn't defined the notion of motion in the proper sense that is unique to a body. Descartes does not appear to be a relativist in the sense of one who maintains that it cannot be said categorically of a body that it moves or is at rest. Rather he is a relationist about true motion, in that his analysis of true motion does not appeal to a fixed background space, but instead to certain select relations a body has over time to certain other bodies.

\footnotetext{
${ }^{9}$ All references are to Descartes' Principia philosophiae from 1644. Newton read most of Descartes works, including the published letters, probably from the collected philosophical works (Descartes 1650).
} 
There is a hint, though, that at a deeper level Descartes embraced a form of relativism. The postil to Article 30 promises an explanation of why it is that, of two contiguous bodies that separate from one another, one rather than the other is said to move. At the close of the article he adds:

But meanwhile it will be kept in mind that all that is real and positive in moving bodies, by means of which they are said to move, is found also in those other contiguous bodies which nevertheless are regarded as only at rest.

This harks back to Article 29, where Descartes notes that transference is reciprocal: it is impossible to understand a body $A B$ to be transferred from the vicinity of a body $C D$ without understanding $C D$ to be transferred from the vicinity of $A B$. He concludes that, if we want to attribute to motion a nature entirely its own and not in reference to something else, then we would say that there is as much motion in the one as in the other. What might this mean?

Dan Garber $(1992,167)$ has linked the closing sentence of Article 30 to what purports to be transcriptions of annotations made by Descartes in one of his own copies of the Principles. ${ }^{10}$ For reasons of space, I quote the shorter of the two.

Motion and rest differ truly and modally if by motion is understood the separation of two bodies from one another, and by rest the negation of that separation. However, when one of two bodies which are separated from one another is said to move, [and] the other to be at rest, in this sense motion and rest do not differ except in reason. (656-7)

Thus, for Descartes, there are circumstances under which a body can be said to be at rest absolutely, viz., when there is no separation from immediately contiguous bodies. And there are circumstances under which a body moves absolutely, viz., when there is separation from immediately contiguous bodies. In this sense, motion and rest are, for Descartes, genuine contradictories. There is also a second sense of motion and rest, let us say motion* and rest*, that kicks in when a body moves absolutely in the first sense, i.e., separates from another body. Then there is no fact of nature determining which body moves* and which body rests* since this is a distinction only in reason. So, a body may move absolutely and move*, or move absolutely yet, without paradox, be at rest*.

Since presumably motion in the proper sense, as defined in Art. 25, must be a quantity in order to enter into the laws and rules of collision, the problem arises how the above sense of motion can be squared with Descartes' repeated claim that each body has only one motion proper to it (Art. 28 and 31). Which, if any of these senses of motion can be identified with motion in the proper sense? Motion* and rest* appear to be unsuitable candidates, since "reason" can make different assignments. Furthermore, it's difficult to see how mere distinctions of reason can have causal efficacy in determining, say, the outcome of collisions. On the other hand, absolute motion in the first sense is a qualitative, not a quantitative matter. There can be little doubt that Descartes was committed, in practice,

\footnotetext{
${ }^{10}$ These are from a manuscript belonging to Leibniz found in the Royal Library of Hanover and included in vol. 11 of Adam and Tannery, 1909.
} 
to the thesis that each body has a unique state of motion (or rest). His laws of motion and rules of collision suppose as much. In particular, the third law and collision rules 4 through 6 presuppose a unique state of rest. It is, perhaps, no wonder that followers such as Regius $(1646,7)$ and Rohault $(1671,56-7)$ confined themselves to the definition of motion in the proper sense and the uniqueness thesis, even if they had been aware of Descartes' deeper ruminations into the nature of motion.

\section{De gravitatione}

Crucial for our purposes, however, is Newton's understanding of Descartes' doctrine of motion. He was hardy privy to the personal annotations that shed light on the cryptic remarks in Articles 29 and 30 noted above. So, it should not surprise us if he understood Descartes to espouse a relationist account of true motion and rest, traditionally understood as contradictories.

Fortunately, we have a manuscript in Newton's hand, in which he summarizes what he takes Descartes' doctrine to be. This untitled manuscript, bearing the incipit De gravitatione et aequipondio fluidorum, is now standardly referred to as simply De gravitatione, or even just De grav. ${ }^{11}$ Of uncertain date, it can be judged from internal evidence to have been written before 1685, although how much earlier is not certain. Descartes' doctrine is summarized in three propositions: 1st, that according to the truth of things [ex rei veritate], only one proper motion suits each body, namely, that as defined in Bk. II, Art. 25 above; 2nd, that, in this definition, a body can be understood to be not only some material particle or a body whose parts are at rest among themselves, but a conglomerate of matter that is transferred simultaneously, even if it consists of many parts which move amongst themselves; and 3rd, that, in addition to this proper motion, a body can have innumerable other motions in virtue of its participation in the proper motions of other bodies of which it is a part, although these additional motions are not proper motions of the body in question, but instances of what Descartes defined as motion in the vulgar sense, viz., the action by which a body migrates from one [relative] place to another. In short, Newton understands Descartes to distinguish true from merely apparent motion and to propose that the true motion of a body can be defined as a special instance of its motion with respect to other bodies, viz., to those that are immediately ambient and viewed as being at rest.

Newton provides this summary because, at the outset, he defines place to be a part of space that something fills and body to be that which fills a place, so that space and body are distinct from one another, contrary to the central tenet of Descartes' doctrine. ${ }^{12}$ Thus, after summarizing that doctrine in the three propositions above, Newton proceeds to the task of disposing of Descartes' fictions [figmenta], presenting three arguments to the effect that Descartes contradicts himself, followed by eight arguments deriving absurd consequences

\footnotetext{
${ }^{11} \mathrm{~A}$ transcription and English translation is published in (Hall and Hall 1962). Gernot Böhme has published a facsimile together with a facing German translation (Newton 1988). An amended version of the Hall and Hall translation, due to Christian Johnson, appears in Andrew Janiak's selection of Newton's philosophical writings (Newton 2014).

${ }^{12}$ Next, Newton defines rest to be continuance in the same place, and motion to be change of place.
} 
from the doctrine. Space does not permit examining these in detail here. Suffice it to say, among these can be found precursors to almost all the Scholium arguments from the properties, causes and effects of true rest and motion. ${ }^{13}$

Following the attack on Descartes' doctrine, Newton sets out his positive characterization of the nature of extension and, as a byproduct, time as well. Whereas one might view Descartes as attempting to construct a new physics out of Aristotelian prime matter alone, Newton's heritage traces back to ancient atomism, specifically Epicureanism as revived and Christianized by Gassendi and disseminated in Walter Charleton's Physiologia EpicuroGassendo-Charltoniana (1654), which Newton read as an undergraduate. ${ }^{14}$ For Gassendi, space and time are neither substances nor accidents, but are res veras or realia Entia $(1658,179)$ fitting into a category of their own. Following suit, Charleton describes space and time as Realities, Things, or not-Nothings (66). Both maintain that space is not just uncreated, but wholly independent of God. Newton likewise denies that extension is either a substance, or an accident inhering in a subject, or else nothing at all. However, he parts company in a couple of respects. First, space is not independent of God because it does not subsist absolutely by itself, but is, as it were [tanquam], an emanative effect of God (99) and a certain affection [affectio] of all being, approaching more nearly the nature of substance than that of accident. Second, whereas Gassendi and Charleton follow Aristotle in retaining corporeal extension as an accident of body but add incorporeal extension to their ontology (the two being everywhere capable of interpenetration), Newton recognizes only one fundamental species of extension, viz., incorporeal. He sets forth an admittedly speculative account of the nature of body according to which bodies are just bounded [determinatas] quantities of extension which God subjects to certain conditions: (1) they are mobile in the sense that they can be transferred from one part of space to another ${ }^{15}$ (2) they cannot penetrate one another and thus suffer collisions subject to certain laws, and finally (3) they can excite various perceptions of the senses and of the imagination in created minds and in turn be moved by these. Thus, corporeal extension is just a type of incorporeal extension qualified in this manner.

\section{The Scholium Itself}

As mentioned earlier, the Scholium divides thematically into three parts. First Newton lays out his explications of the terms tempus, spatium, locus and motus. ${ }^{16}$ Second come the arguments in defense of these explications. Third, in the long final paragraph, is the

\footnotetext{
${ }^{13}$ For a detailed comparison, see my entry, "Newton's Views on Space, Time and Motion" in the online Stanford Encyclopedia of Philosophy.

${ }^{14}$ Newton likely read Lucretius as well. It is not known whether he was familiar with either (Gassendi 1649) or (Gassendi 1659). (Charleton 1654) is supposed to be based on the former. For further discussion see McGuire and Tamney (1983) and Jalobeanu (2007).

${ }^{15}$ This is to be distinguished from numerically the same parts of space being mobile. That would constitute a return to Descartes' doctrine.

${ }^{16}$ It might be complained that Newton did not systematically distinguish between the two types of definitions, of names vs. of things, in manuscripts leading up to the Principia. De gravitatione officially defines, inter alia, place, rest and motion, but also, after his critique of Descartes such technical notions
} 
illustration of how the true motions can be known empirically. Rather than treat these seriatim, let us look at the justifications along with the definitions. ${ }^{17}$

5.1. Time. According to Newton, absolute, true and mathematical time, which, by another name, is just duration, flows uniformly in itself and by its own nature without relation to anything external. Relative, apparent, and common [vulgare] time is any perceptible measure of duration by means of motion, either accurate or nonuniform,. Relative times are used in place of true time in everyday life. Examples are the hour, the day, the month, and the year.

Neither De gravitatione nor the Scholium critiques Descartes' views on duration and time, probably in part because they do not play a prominent role in Principia philosophae and in part because Descartes' treatment of them there is somewhat confusing. ${ }^{18}$ Nor does he here. Instead, he claims that absolute time is distinguished from relative time in astronomy by the equation of time. The standard for time keeping in ordinary affairs was the natural, or true solar day, i.e., the time it takes for the sun to successively pass the meridian as indicated by a sun dial, which most people (Descartes included) assumed to be constant. However, astronomers since antiquity realized this varies throughout the year due the the nonuniform motion of the sun along the ecliptic and the declination of the

as the intension, the extension and the absolute quantity of a power. These latter surely count as definitions of names while the former definitions of things. Hence, Newton did not uniformly distinguish the two types of definitions. There is another preliminary manuscript, De motu corporum in mediis regulariter cedentibus, dated by Whiteside to Winter 1684/5, MS. Add. 3965.5a, folios 24r-26r, 23r-24r, facsimile in (Whiteside 1989, 28-33) and online at http://cudl.lib.cam.ac.uk/view/MS-ADD-03965/49, transcription online at http://www.newtonproject.sussex.ac.uk/view/texts/normalized/NATP00091 and with translation in (Herivel 1965, 304-315), which mixes them as well, listing as such definitions of absolute and relative time, space, place, rest and motion prior to, e.g., innate force, impressed force and so on. In response, a number of things can be said. For one, this does not count against what can be established about the Scholium on the basis of internal evidence. Rather it shows Newton revising toward a more perfect exposition. The earlier pattern is likely due to his determination to emulate a mathematical style whereby all proceeds from definitions and postulates. For another, it's not always so clear, in general, whether a definition is nominal or real, particularly in mathematics. Which is it to define a point as that which has no parts? Notable in these earlier manuscripts is the appearance of the definition of body [corpus], in De grav as that which fills place and in De motu coporum ... as that which is movable but unable to penetrate other bodies. The latter we might judge as a real definition, but what of the former?

${ }^{17}$ This is Newton's style in the preliminary manuscript De motu corporum in mediis regulariter cedentibus.

${ }^{18}$ On the one hand, Descartes asserts in Book I, Article 55 that the duration of a thing is only a mode under which we conceive of that thing insofar as it continues to be. In Article 56, however, he remarks that the existence and duration in things that exist and endure ought to be said to be attributes in that they inhere in those things in an invariant way. Article 57 then announces that certain attributes exist in things themselves, but others only in thought. The postil furthermore promises an explication what duration and time. Since these are the only items considered here, one might expect that they will illustrate the distinction. Indeed time, which, in its capacity as the measure of motion, is identified with the duration of the greatest and most uniform motions, resulting in the day and the year, adds nothing but a mode of thought to duration taken in general. This suggests that, by way of contrast, the duration of a thing is in the thing itself. But that doesn't square with what's said about duration in Article 56. For more on Descartes on time and duration see (Gorham 2007, 2008) and (Waller 2014). 
ecliptic to the celestial equator. This has to be corrected to the mean solar day in order to obtain an equable standard to measure celestial motions.

Now whether this in itself is supposed to constitute an argument for the distinctness of absolute from relative time is less than clear. What follows, though is a clearly identifiable argument, built out of two sub-arguments. The first takes for its premise that any motion can be accelerated or retarded (presumably by the application of an external force). Hence, it is physically possible that there is no uniform motion by which to accurately measure time. The second sub-argument has for a premise that the duration or perseverance of the existence of things is independent of whether motions are swift or slow or none at all. From this it follows that the true or equable progress of absolute time is not liable to change. Combining the two sub-conclusions, it follows that we could have a world with a uniform passage of absolute time but no uniform motions. Therefore, absolute time is justly distinguished from its sensible measures and instead inferred from the equation of time in astronomy. Newton adds to this that the necessity for the equation of time is evidenced not only by experiment with the pendulum clock, but also by the eclipses of the satellites of Jupiter. ${ }^{19}$

5.2. Space. In De motu corporum in mediis regulariter cedentibus, Newton defines absolute space as that which by its own nature without relation to anything else always remains immobile. The Scholium makes two slight additions. First it remains immobile without relation to anything external, and second it remains not only immobile but similar [similare]. The question arises, what does Newton mean by the latter? Cohen and Whitman (1999) translate similare as 'homogeneous', which is a reasonable interpretation. Unfortunately, Newton never argues that space has this property, only that it is immobile.

The arguments for immobility in De motu corporum in mediis regulariter cedentibus and in the Scholium are the same. Newton invokes a comparison with time. Just as the order of its parts are unchangeable, so is the order of the parts of space. Were they to move from their places, they would move from themselves, which is presumably absurd. The reasoning is that, just as all things are placed in time as far as order of succession, all things are placed in space as far as order of position [situs]. This includes times and places themselves. (In De gravitatione Newton contends that any being that exists must be in space and time. Insofar as times and spaces are beings, they must be so themselves.) They are their own places, and hence should a part of space move, it would have to move out of itself. Newton adds that it is of the essence of places that they be places, and for primary places to move is absurd.

Importantly, Newton is not arguing that amongst all possible frames of reference, as one might say now, or amongst all relative spaces, and in particular, amongst the inertial ones, there is a distinguished rest frame. The question of the mobility of space concerns whether the parts move inter se. In De gravitatione, if space were to move as a whole, there would

\footnotetext{
${ }^{19}$ For further elaboration on the problem of the equation of time in the seventeenth century, see (Rynasiewicz 1995a). For a different perspective, see (Schliesser 2013). For more on Newton's interest in timekeeping see (Add. 4005, fol. 43) and (Add. 4005, fol. 51-52) in Hall and Hall 1962, pp. 386-391 and pp. 392-393, respectively.
} 
have to be a second space (immobile as far as motion inter se is concerned) from which, or with respect to which, it moves, an idea Newton there finds silly enough as to need no refutation. The apparatus of relative spaces is a Newtonian invention, though it is implicit in Descartes and in mathematical astronomy. A relative space is simply not on the same ontological footing as space itself.

A relative space, according to Newton, is any mobile measure of absolute space, i.e., mobile with respect to absolute space (not with parts mobile inter se), which is defined by our senses by means of its position [situs] with respect to bodies. People commonly (but mistakenly) use relative spaces, in particular, as defined by the earth, in place of immobile space. As examples he cites the measure [dimensio] of a subterranean space, an aerial space, or a celestial space defined by its position with respect to the earth. The defining body determines the state of motion of the relative space (they co-move) but, as is clear from the examples, not its extent. A subterranean space would presumably be the space inside a cave or a mine shaft, or perhaps the entire region bounded by the surface of the earth, and thus finite in extent.

So, relative spaces do not have to be, as we would say, global. ${ }^{20}$ This may be confusing, since Newton goes on to say that absolute and relative space are the same in "species and magnitude," suggesting that a relative space must be infinite in extent. Here, I think the problem lies with the absence of definite and indefinite articles in Latin. In the argument for the immobility of absolute space, we found Newton speaking of parts of absolute space as spaces themselves. Moreover, in Corollary V to the laws, Newton talks about a system of bodies enclosed [inclusorum] in a space that may or may not be moving. So, I suggest that we understand Newton to be saying that an absolute and $a$ relative space are the same in "species and magnitude," where by the Latin word species he means form or figure. The gist is then that any relative space coincides with some part of absolute space, although, as he makes clear, that may not be the same part from moment to moment (and that's the sense in which relative spaces are mobile).

5.3. Place. Newton defines the place [of a body] to be that part of space which the body occupies, and is absolute or relative according to whether the space is absolute or relative. Immediately upon giving the definition, he dismisses two alternative definitions, both of which in De gravitatione he attributes to Descartes. ${ }^{21}$ One is the the location [situs] of the body. The other, dating back to Aristotle (Physics IV.A.1-5), is the enclosing surface. Newton dismisses the first on the ground that, properly speaking, locations do not possess quantity and are not so much places as affections of places. The second he finds unsatisfactory in that the places of equal solids are always equal, whereas their surfaces are frequently unequal due to a dissimilarity in shape. This argument makes sense only if by equal solids Newton does not mean congruent solids, but only solids of equal volume, and similarly for the places occupied. But, one might wonder, where does the constraint that places of solids of equal volume must be equal come from? A more convincing reason

\footnotetext{
${ }^{20}$ To my knowledge Ric Arthur was the first to point this out (Arthur 1994).

${ }^{21}$ Stein (1967) was the first to point out that, in the Scholium, Descartes more than anyone else is Newton's target.
} 
that Newton gives for dismissing surfaces as places is that the motion of the whole is the same as sum of the motion of the parts, i.e., the translation of the whole from its place is the same as the translation of the parts from their places. Therefore, the place of the whole is the same as the sum of the places of the parts, and hence is internal and in the entire body.

5.4. Motion. Given this definition of place, Newton can characterize motion as change of place, in other words, the absolute motion [of a body] is the transference of the body from one absolute place to another, while relative motion is the transference from one relative place to another. Newton provides a long example of how the absolute motion of a body can be decomposed into a series of relative motions of a sequence of bodies by adding in the absolute motion of the final body. Specifically, the absolute motion of a body on a ship under sail at sea will be the relative motion of the body with respect to the ship compounded with the motion of the ship with respect to the earth compounded with the absolute motion of the earth through absolute space.

Two paragraphs later, after arguing for the distinctness of absolute and relative time, and after arguing for the immobility of space, Newton explains that, because of the imperceptibility of absolute space, we are forced to use relative places and motions in their stead, which suffices for ordinary affairs but not in philosophy. For, he says, there may be no body that is truly at rest. This in essence is to say that absolute space is genuinely distinct from relative space in that it cannot be defined to be any particular one of the myriad of relative spaces.

The following paragraph opens: "But $[$ autem $]$ rest and motion, absolute and relative, are distinguished from one another by their properties, causes and effects" (12). Newton provides five arguments as to why absolute and relative motion and rest are distinct from one another. Three are from the properties of rest and motion, one from the causes of motion, and, lastly, one from its effects. Before I detail these arguments, here is the crucial insight. (The reader would do well to keep it in view throughout the account, up to the Scholium's final paragraph.) Newton assumes that true motion and rest are real states of bodies. But he does not assume that true motion is definable as or consists in transference from one absolute place to another. Rather, the five arguments (from properties, causes and effects) collectively aim to establish that claim. Namely, Newton aims thereby to justify his definition of true motion - and also to invalidate alternative, relationist definitions of true motion. Thus, if one buys into the premises about properties, causes or effects in the respective arguments, which Newton thinks one should, then relationist accounts of true motion and rest can be ruled out as flatly inadequate. Since Newton's own definition of true motion satisfies the premise in each case, that definition is left standing as the only reasonable one. Indeed, the third argument from properties argues directly for it.

1. It is a property of rest that bodies truly at rest are at rest among themselves. The argument seeks to show that the true rest of a body $b$ cannot be defined in terms of its position [situs] among bodies in any finite region $R_{b}$ surrounding it. Let $\varphi\left(b, R_{b}\right)$ be the defining condition. By hypothesis, whether or not $\varphi\left(b, R_{b}\right)$ holds does not depend on the state of motion or rest of any body outside of $R_{b}$. So, imagine a distant body $b^{*}$ truly at 
rest outside of $R_{b}$. The condition $\varphi\left(b, R_{b}\right)$ may well be satisfied even if $b$ does not maintain a fixed position with respect to $b^{*}$. Therefore, $\varphi\left(x, R_{x}\right)$ is an inadequate definition of ' $\mathrm{x}$ is truly at rest' for any choice of $R_{x}$.

2. It is a property of motion that those parts of a moving body that maintain fixed positions with respect to the body as a whole participate in the motion of the entire body. Reasons to believe this are that, in the case of a revolving body, all the parts endeavor to recede from the axis of motion, and that, in translational motion, the impetus of a body arises from the conjunction of the impetus of the individual parts. The argument is intended to show that true and absolute motion cannot be defined as the translation from the neighborhood of bodies regarded as being at rest [quae tanquam quiescentia spectantur]. This is almost verbatim Descartes' definition of true motion. Missing is only the explicit requirement that these bodies be immediately contiguous. But that can be surmised from context. In any event, if the argument goes through, it defeats Descartes' definition of motion in the proper sense.

The argument proceeds as follows. It ensues immediately from the property of motion that, when a system of bodies encloses another, if the ambient bodies are in motion, then an enclosed body at rest relative to the ambient bodies moves truly. But according to the Cartesian definition, if one simply regards the ambient bodies as being at rest, it follows that the enclosed body is truly at rest, contrary to what is the case. The body is truly at rest only if the ambient bodies are truly at rest, not just considered to be at rest. For if they are really in motion, then so is the enclosed body. As Newton puts it, when the kernel is at rest in the shell and the shell moves, so does the kernel.

3. A property similar to the preceding, according to Newton, is that what is placed in a moving place moves along with that place. If a body moves from a moving place, it also participates in the motion of the place insofar as the body's total motion is compounded from its motion from the place and the motion of the place. The motion of the latter may again consist of a [relative] motion out of another moving place compounded with the [true] motion of the second moving place, and so on. Barring an infinite regress, one must eventually arrive at an unmoved place. as in the example of the ship above. Otherwise it may be impossible to assign a definite true motion to the body. Thus, the total [integri] and absolute motion of a body cannot be defined without making reference to unmoved places. As Newton says, this is the reason he earlier referred such motions to unmoved places and relative motions to to movable places. Furthermore, the only unmoved places are those which from infinity to infinity keep fixed positions relative to one another, and hence always remain unmoving, thus constituting the immovable space that is absolute space.

4. The causes by which true and relative motion are distinguished from one another are the forces impressed on bodies to generate motion. The argument here has two prongs.

(a) It is a premise that true motion is neither generated nor changed unless a force is impressed on the body. However its relative motion can be generated or changed without impressing forces on it. For it suffices to impress forces on all the other bodies that determine the relative space with respect to which the relative motion of the body is 
defined. When these bodies yield to those forces, the relative rest or motion of the original body is changed.

(b) On the other hand, it is also a premise that true motion is always changed by forces impressed on a moving body. ${ }^{22}$ But its relative motion is not necessarily changed by such forces. For if the same [accelerative] forces are also impressed on the bodies which define the relative space with respect it moves, the resulting relative motion will be the same.

Putting the two prongs together, any relative motion can be changed while the true motion is preserved, and any relative motion can be preserved while the true motion is changed. Therefore, true motion in no way consists in such relations.

5. The effects which distinguish absolute and relative motion from one another are the forces of receding from the axis of rotation in circular motion. Newton takes it as a premise that in merely relative circular motion, these forces are null, while in true and absolute circular motion they are greater or lesser depending on the quantity of motion. Consider, now, the following experiment (which Newton indicates he actually performed). Hang a bucket by a very long string, turn it around again and again until the string is stiffened from being extremely twisted, and then fill the bucket with water so that it together with the water is at rest. Then with a sudden force set it turning in the opposite direction, and let the thread unwind so that it persists in this motion for a very long time. Initially, the surface of the water will be flat, just as it was before the motion of the bucket. But afterwards, by gradually impressing a force on the water, the bucket will cause the water to begin to rotate sensibly, to recede gradually from the center, and to ascend the walls of the bucket. With an ever faster motion, it ascends more and more, until it completes revolutions in equal time with the bucket and thus is at rest relative to it.

The ascent of the water indicates an endeavor to recede from the axis of motion, and by such endeavor the true and absolute circular motion of the water is revealed and can be estimated. However, with relative motion everything is the contrary. Initially, when the relative motion of the water with respect to the bucket is greatest, that relative motion produces no endeavor to recede from the axis: the water does not seek the circumference by ascending the sides of the bucket, but remains level, indicating that the true circular motion of the water has not begun. Afterward, as the relative motion of the water lessens, its ascent up the sides of the bucket indicates an endeavor to recede from the axis, and this endeavor indicates the true circular motion of the water constantly increasing and finally reaching a maximum when the water is at rest relative to the bucket. This shows that this endeavor does not depend on a translation of the water with respect to ambient bodies, i.e., in this instance, the bucket. Therefore - and this is the conclusion of the argument from effects - true circular motion cannot be defined in terms of such a translation, which is precisely the Cartesian definition of true motion in this instance.

To review, these arguments attempt to show the following. Two of them-the one from effects and the second one from properties - directly assail Descartes' definition of true motion. Another two of them-the first from properties and the one from causesseek to rule out in general relational definitions of true motion and rest. The remaining,

${ }^{22}$ Assuming, of course that the net force is non-null. 
viz., the third argument from properties, attempts to establish directly that an adequate definition of true motion requires reference to unmoving places, and thus that there is an immobile space. By ruling out actual or potential competitors, the arguments with negative conclusions can be thought of individually as enthymemes for disjunctive syllogisms, or arguments by elimination. But there is no global argument per se from properties, causes and effects.

That Descartes remains the prime target is evident in that Newton subsequently addresses what the properties, causes and effects of motion indicate for the Cartesian system of the world. According to Descartes, the earth and the other planets are are swept about the sun by a vortex of subtle matter. Since they are at rest with respect to their immediate surroundings, they are truly at rest on his definition of true motion, a thesis which Descartes explicitly affirms. But, from the foregoing, this can't be right. For the planets change their positions with respect to one another, which is never the case for bodies at rest (property 1). Also, they are carried along with the subtle matter of the vortex, and so participate in its (true) motion (property 2). Finally, as parts of a revolving a revolving whole, they endeavor to recede from the axis of rotation (effects). ${ }^{23}$

Newton continues to criticize Descartes in the next paragraph. After the general conclusion of the Scholium, that the relative quantities are not the very quantities whose names they bear [i.e., the absolute quantities] but only sensible measures of them (true or inaccurate) commonly used in place of them, Newton explains that, if usage is a guide to meaning, then the relative quantities are ordinarily to be understood as the referents, particularly in the scriptures. ${ }^{24}$ He accuses those who take them there to be the true quantities of inflicting violence on the scriptures. Nor do they less corrupt mathematics and philosophy when confounding the true quantities with their relative and ordinary measures.

\section{Finding the True Motions}

Up to now, Newton has built a case that the true quantities (time, space, place, and motion) are ontologically distinct from their relative counterparts. For motion in particular, he has argued that the true motion of a body cannot be defined as any particular species of its motion relative to other bodies, and that transference from one absolute place to another is the appropriate definition of true and absolute motion.

6.1. The Ultimate Paragraph of the Scholium. At this point, Newton turns to an epistemological issue in the lengthy final paragraph of the Scholium. Because the parts of

\footnotetext{
${ }^{23}$ Descartes also attributes to them such an endeavor even though for him they are officially at rest. Newton criticizes Descartes for this in De gravitatione.

${ }^{24}$ Newton thus follows Vincent Wing, who writes in his Preface "To the Judicious Reader" ... whatsoever is there spoken of the Earths [sic] Rest, or the Suns [sic] Motion. Psal. 92, Psal. 103. Eclesiast. 1. Psal. 18. Isa. 38. Ecles. 48, etc. is to be understood: secundum nostram apprehensionem, $\&$ communem loquendi modum, non secundum rerum naturam, as the Philosophers say; according to our apprehension and vulgar manner of speaking, and not according to the nature of the things; ... (Wing 1651).
} 
immobile space in which bodies truly move do not affect the senses, it is very difficult to recognize [cognoscere] the true motions of individual bodies and in actuality to separate [discriminare] them from the apparent. However, he says with a touch of irony, the cause is not entirely desperate. For arguments are at hand, partly from the apparent motions, which are the differences of true motions, and partly from the forces which are the causes and effects of true motion. As an illustration, Newton introduces a thought experiment of two globes connected by a thread at a fixed distance from one another revolving about their common center of gravity. The endeavor of the globes to recede from the axis of motion can be known [innotescere] from the tension in the thread. Then, from their endeavor to recede it is possible to calculate [computare] the quantity of circular motion. Finally, by applying equal forces to opposite faces of the globes and discovering whether that increases or decreases the tension in the thread, it is possible to discover [cognoscere] whether the motion is in the clockwise or the counterclockwise direction. Moreover, all this can be done in an immense vacuum in which there is nothing external and sensible with which to compare the globes. Alternatively, if there are distant bodies maintaining fixed distances among themselves, as is the case with the fixed stars, it cannot be known [scire] from the relative rotation of the globes with respect to them whether the globes or that system of distant bodies is truly rotating. However, by attending to the tension in the thread, it can be discovered [invenire] which system is in motion. And in this instance, whether the rotation is clockwise or counterclockwise can be inferred from the apparent motion of the globes relative to those bodies. As mentioned earlier, Newton concludes:

However it will be shown more fully in what follows [how] to infer [colligere] the true motions from their causes, effects and apparent differences, and conversely, from the motions, whether true or apparent, [to infer] their causes and effects. For this is the end to which I composed the following treatise. (11; CW 415)

Thus, we should expect Newton in the end to reckon these true motions.

6.2. Corollaries to the Laws. Certain corollaries to the laws of motion, though, appear to stand in the way. Corollary IV states that the common center of gravity of all bodies acting upon one another is (barring external actions and impediments) either at rest or else in motion uniformly in a straight line (17; CW 421). Hence, for example, in the case of the revolving globes in an otherwise empty space, the absolute rotational motion of the respective globes may be discernible by measuring the tension in the cord but, even assuming no external influences, it remains underdetermined whether the common center of gravity is at rest or in uniform rectilinear motion.

Corollary V reads, "The motions of bodies enclosed in a given space are the same among themselves, whether that space is at rest, or moves uniformly in a straight line without circular motion" (19; CW 423). Newton alludes to Galileo's thought experiment: "This is born out by a brilliant experiment. All motions take place in the same way in a ship whether it is at rest or moves uniformly in a straight line" (19; CW 423). The corollary is commonly cited as Newton's formulation of Galilean relativity. Whether the ship is 
absolutely at rest or in absolute rectilinear motion, there appears to be no experiment that can be done on the ship capable of detecting the difference.

To make matters appear even more desperate, Corollary VI goes on to state that the motions will remain the same among themselves even if the same accelerative force ${ }^{25}$ is applied equally. The corollary plays a crucial role in Book III in the argument for universal gravitation by permitting the system of Jupiter and its satellites, which is in free fall, to be treated as though it were at rest.

Corollary IV indicates there can be no direct proof, say, of the state of motion of the center of mass of the solar system from the motions of its constituents and the forces acting inter se, something quite apparent to Newton. Some take this to suggest a much stronger conclusion. What appears as Hypothesis I after the argument for universal gravity in Book III of the 2nd and 3rd editions of the Principia, has, in particular, attracted attention, especially in light of Newton's claim in the General Scholium, added to those editions, that hypotheses have no place in experimental philosophy. Hypothesis I states that the center of the system of the world is at rest, something, Newton tells us, no one doubts, although some contend that the earth is at rest in the center, others the sun. ${ }^{26}$ It has been suggested that, in the light of Corollaries IV-VI, the hypothesis does not state a proposition Newton took stock in, or else does not state a proposition at all, but amounts to either a dialectical maneuver (DiSalle 2002, 56, n. 38) or a convention (Harper 2011, 98). If so, it follows that Newton did not believe there is a fact of the matter as to the absolute velocities of individual bodies and that his ontological commitment to absolute space was thereby less than robust.

6.3. Hypothesis III of the 1st Edition. But how, then, is one to make sense of the Scholium to the definitions, which appears in all three editions without substantial change? Why does Newton argue, apparently in earnest there, that true motion cannot be identified with any form of the relative motion of bodies, but instead requires for its proper analysis the existence of immovable places and thus of absolute space? And why would Newton assert in the concluding General Scholium of the 2nd and 3rd editions that, by existing always and everywhere, God constitutes [constituit] duration and space?

Hypothesis I of the 2nd and 3rd editions (hereafter $\mathrm{E}_{2}$ and $\mathrm{E}_{3}$, respectively) appears in the first edition $\left(\mathrm{E}_{1}\right)$ as Hypothesis IV at the beginning of Book III, together with eight other hypotheses. The first two of these hypotheses become Rules I and II of the Regulae Philosophandi in subsequent editions, while the last five become Phænomena I and IIIVI. ${ }^{27}$ This tempts us to argue as follows. Surely, Newton sought to construct a sound argument for the thesis of universal gravitation, not just an argument that would trick the Cartesians (and Aristotelians) using premises that they would deem acceptable, even if Newton did not. Thus, the opening hypotheses should be propositions Newton found

\footnotetext{
${ }^{25}$ That is, a force producing the same accelerations.

${ }^{26}$ Newton proceeds to identify the center of the system of the world with the center of mass of the solar system. According to Corollary IV, that center will either be at rest or else move uniformly in a straight line. Since the hypothesis rules out the latter, it follows that the center of mass is at rest.

${ }^{27}$ Phenomenon II, stating that the satellites of Saturn obey Kepler's 1st and 3rd laws, is new to $\mathrm{E}_{2}$.
} 
passable in his own mind. In particular, the reader should not be expected to have to ferret out from the rest a hypothesis Newton does not endorse, i.e., allegedly Hypothesis IV of $\mathrm{E}_{1}\left(=\right.$ Hyp. 1 of $\mathrm{E}_{2}$ and $\left.\mathrm{E}_{3}\right)$.

A potential difficulty with this reading is that it does not allow that Newton might have been cagey about his own deep beliefs, and, in claiming that everyone accepts Hypothesis IV $\left(\mathrm{E}_{1}\right)$, he really means everyone else. This is of real concern. For I. B. Cohen $(1956,1966 \mathrm{~b})$ has argued that, in fact, Newton did not believe the previously unmentioned Hypothesis III. It reads,

Any body can be transformed into a body of any other kind and successively assume all intermediate degrees of qualities. (402, CW 795)

This is dropped in later editions and Rule III added to the Regula Philosophandi.

One consideration adduced by Cohen comes from David Gregory's notes on $\mathrm{E}_{1}$, where he writes,

This the Cartesians will easily concede. Not so the Peripatetics, who put a specific difference between celestial and terrestrial matter. Nor the adherents of Epicurus's philosophy, who posit atoms and immutable seeds of things. (Quoted in Cohen 1966, 171; trans. mine.)

These Epicurean atoms and immutable seeds come in various sizes and shapes that obviously cannot be transformed into one another by natural means. So, how could Hypothesis III represent the view of an atomist like Newton, who confesses in Query 31 of the Opticks,

... it seems probable to me, that God in the Beginning form'd Matter in solid, massy, hard, impenetrable, moveable Particles, of such Sizes and Figures, and with such other Properties, and in such Proportion to Space, as most conduced to the End for which he form'd them? (Newton 1718, $375-376)$

However, the universal transformation of matter is possible for an atomist if the atoms are sufficiently homogeneous. If Newton were such an atomist at the time of drafting Book III, the possibility is open that he just changed his mind about Hypothesis III in the transition from the 1st to the 2nd edition. To rule this out, Cohen's adduces various annotations of $\mathrm{E}_{1}$ and manuscript drafts leading up to the formulation of Rule III. Examination of these would take us too far afield. Suffice it to say that there is a pair of passages that Cohen does not take into account, suggesting the contrary.

One is from the drafted Conclusio for $\mathrm{E}_{1}$ that was never published (Add. 4005, fols. 25$28,30-37)$. Newton there discusses how attractive and repulsive short range forces acting on atomic configurations can account qualitatively for chemical and physical properties and processes, including transmutation. E.g., by fermentation, water can change into such denser substances as animal and vegetable matter, salts, stones and various earths, and eventually, given enough time, into minerals and metals.

For the matter of all things is one and the same, which is transmuted into innumerable species by natural operations, and the subtler and rarer bodies 
[water] are wont to be thickened and condensed by fermentation and [the power of] vegetation. (Hall and Hall 1962: 328, 341)

Thus, unless one drives a wedge between the Conclusio and the drafting of the Hypotheses, it certainly appears that Newton found Hypothesis III acceptable.

A second passage suggests that Newton may not have even changed his mind re transmutation. Query 30 of the Opticks asks,

Are not gross Bodies and Light convertible into one another, and may not Bodies receive much of their activity from the Particles of Light which enter their Composition? (Newton 1718, 349)

The suggestion appears to be that matter consists of various configurations of spectral particles of light. This is reinforced at the beginning of the next paragraph:

The changing of Bodies into Light, and Light into Bodies, is very conformable to the Course of Nature, which seems delighted with Transmutations. (Ibid.)

The particles of a given substance are themselves complex constructions containing interstices and sub-particles, and so on, until the ultimate atoms are reached. As we learn from the Conclusio,

...these [ultimate] particles in no way will be piled up in the manner of stones, but they join together like crafted and highly regular structures, as in the formation of snow and salt. Undoubtedly, they can be shaped into very long and elastic twigs [or rods: virgas] and [then] into net shaped particles by the binding together of the twigs and [then] into larger particles by the combination of these and finally into sensible bodies according to geometric laws. (Hall and Hall 1962: 327-328, 341; trans. mine)

If the ultimate particles are interchangeable, the possibility for transmutation is clear.

But, as mentioned earlier, there are annotations and documents which, Cohen has argued, indicate that Newton was willing to make dialectical use of hypotheses he did not necessarily endorse. ${ }^{28}$ Since it is a major project in itself to assess whether this conclusion is warranted, let us cede this possibility. Fortunately, there are sources that suggest that Hypothesis IV of $\mathrm{E}_{1}$ (= Hyp. I, $\mathrm{E}_{2}$ and $\mathrm{E}_{3}$ ), that the center of the system of the world is at rest, is not one of them.

6.4. The Original System of the World. As Cohen notes, Newton's use of the term 'Hypothesis' evolved over time. Even certain propositions subsequently labeled as laws appear earlier as hypotheses. ${ }^{29}$ Can anything be gleaned concerning his usage in the 2nd and 3rd editions of the Principia? Two other hypotheses occur. ${ }^{30}$ One, at the head of Section IX of Book II (unnumbered in all three editions) reads

\footnotetext{
${ }^{28}$ There is a voluminous secondary literature concerning Hypothesis III. See Biener 2018 for further references.

${ }^{29}$ See, e.g., MS Add. 3965.1, ff. 1r-3v

${ }^{30} \mathrm{As}$ Cohen notes, there are ample occurrences of the word 'hypothesis' in the body of the text. Space hardly permits surveying all of these.
} 
The resistance which arises from the defect of lubrication in the parts of a fluid, other things equal, is proportional to the velocity, with which the parts of the fluid are separated from one another (373; CW 779). ${ }^{31}$

It appears to function as a suppressed antecedent in each of the propositions that follow in that section, and thus appears at the outset as a matter of economy. This contrasts with Hypothesis II of Book III in the 2nd and 3rd editions, to the effect that, in modeling the earth as a ring, it doesn't matter whether you take it to be liquid or solid when calculating the precession of the equinoxes. In the 1st edition, this appears as a lemma without proof, so that its later rendition as an hypothesis may indicate only that Newton still could prove it. (as did Laplace - see Cohen 1966). The question, though, is whether Newton gave credence to the counterfactual, and there appears to be no indication he did not.

Hypothesis I certainly deserves its designation as such insofar as Newton could not prove it. But unlike Hypothesis II, it expresses a proposition that in principle cannot be proved in light of the corollaries to laws of motion, thereby putting it on a different epistemic footing. However, there are additional documents that may help. Before drafting Book III of the Principia, Newton had intended to publish only Books I and II together. The thesis of universal gravitation would be put forward in a separate, less technical work, titled De Mundi Systemate, a Latin text of which was published only in 1728 shortly after his death. ${ }^{32}$ That year there appeared an anonymous English translation followed shortly by a second edition (Newton 1731). In the section bearing the postil Planetas omnes circa Solem revolvi (XXVIII of Add. 3990), there occurs the passage:

...the Sun is moved with no notable force, unless perhaps with such as all the Planets are equally moved with, according to their several quantities of matter, in parallel lines, and so the whole system is transferred in right lines. Reject that translation of the whole system, and the Sun will be almost quiescent in the center thereof. (Newton 1731, 48; the same text appears in (Newton 1728, 32) and Add. 3990, 43-45.)

This could be taken as merely a conditional (if we reject that translation, then ...) OR as a positive recommendation to reject that translation.

Something similar arises in an earlier section (Add. 3990, VIII) having the postil Vim qua Planetae superiores reguntur non dirigi ad Terram. Eandem dirigi ad Solem. "The force which governs the superior Planets is directed, not to the Earth, but to the Sun." Newton 1731.) It might appear to present more of a challenge.

One may imagine that the Sun and Planets are impelled by whatever other force you please, equally and along parallel lines. It is true that, with such a force, (by Cor. 6. of the Laws of Motion) the situation of the Planets among themselves would not be changed, no sensible effect will be produced; however we proceed from the causes of sensible effects. Hence, let us reject

\footnotetext{
${ }^{31}$ For 'defect of lubrication' read 'friction.'

${ }^{32}$ An ancestor manuscript dating from 1685 has survived with the title De Motu Corporum. Liber Secundus (Add. 3990). See http://cudl.lib.cam.ac.uk/view/MS-ADD-03990/.
} 
any force of this sort as dubious, and irrelevant to the phænomena of the heavens; ...

It may help to remind the reader of Rule I (2nd and 3rd editions; Hypothesis I, 1st edition) that no more causes are to be posited than are such as to be both true and sufficient to explain the phenomena. An obvious difficulty with imagining such forces accelerating the solar system as a whole, is that there is no identifiable source of the force. Newton faces a similar situation in considering the hypothesis that the fixed stars rotate about the earth. This would require forces directed not toward any bodies on which they would depend but toward imaginary points along the earth's axis. This sort of hypothesis he calls, in Latin, dura, i.e., troublesome, disagreeable or unacceptable. ${ }^{33}$

At the stage of development parallel to where Hypothesis IV of Book III of the 1st edition of the Principia is put into play, we find the following passage. ${ }^{34}$

Because the fixed [stars] are at rest with respect to one another, we may consider the Sun, Earth and Planets as one system of bodies moving in whatever way among themselves; and the common center of gravity of all (by the fourth corollary of the laws) will either be at rest or will move uniformly forward in a straight line. In the latter case the whole system will likewise move uniformly forward in straight lines. This hypothesis is unacceptable $[$ dura $] .{ }^{35}$ With it rejected, that common center of gravity will be at rest.

If true motion really is transference from one absolute place to another, there certainly must be a fact of the matter as to the whether the center of mass of the solar system is at rest or in motion. It is reasonable to conclude that Newton rejects a common acceleration for all the bodies of the system as being unreasonable: there appears to be no physical cause of such an accelerative force. So it is either in uniform rectilinear motion or at rest. Newton does not give reasons for rejecting the former hypothesis and affirming the latter. It appears he did not feel compelled to. For, as he says in the Principia, the hypothesis is universally accepted.

\section{COnClusion}

There is a stubborn tradition that takes the goal of the Scholium to be to establish first the existence of absolute motion by means of the rotating bucket experiment and the example of the globes and then the existence of absolute space given the definition of absolute motion as change of absolute place.

This commits a number of fallacies. First, although Newton certainly does want to secure the independent existence of absolute space, and even argues directly for it as a

\footnotetext{
${ }^{33}$ It can also mean harsh, but one then has to wonder what it means to call a hypothesis harsh.

${ }^{34}$ The postil for this section reads Planetarum omnium commune gravitatis centrum quiescere $E$ solem tardissimè moveri. Definitur motus Solis.

${ }^{35}$ This sentence is translated in (Newton 1731) as "But this is an hypothesis hardly to be admitted." The translator remains unknown. See I. B. Cohen's learned introduction to the 1969 Dawsons of Pall Mall reprinting.
} 
corollary to the third argument from the properties of true motion, he does not see the need to establish the existence of absolute, i.e., true motion. As we have seen, the reality of true and absolute motion is presupposed in each of the arguments from properties, causes and effects. It is a persistent myth that Galilean relativity in the robust sense - that there is no correlate in reality of absolute rest-had become entrenched prior to the Principia. Those in its grip often refer to the absolute quantities as "newly introduced" theoretical entities. That, they are not. To the contrary, although Newton's arguments for them are unprecedented, to take absolute space and time to be novel with Newton is to ignore the Gassendi-Charleton atomistic tradition, which, at least for the case of space, harks back to Epicurus.

Second, this tradition wrongly construes Newton's characterization of true motiontransference from one absolute place to another - as a definition of a name rather than of a thing, in the jargon of the Port Royal Logic.

Third, the globes are not used to the same end as the bucket. The latter is enlisted to defeat Descartes' definition of true motion. The former serves an epistemological, not an ontological function. ${ }^{36}$

Finally, yet another pervasive misunderstanding takes the goal of the arguments from properties, causes and effects to show how true motion and rest can be empirically distinguished from the merely relative, i.e., to reveal some experimental signature of the absolute. This stems largely from a failure to examine the original text. The operative word is definire, which Andrew Motte in his unauthorized 1729 translation rendered as to determine. Although a reasonable translation in Newton's day, it invites the modern reader to think in epistemic terms, how something can be ascertained. In the case of effects, the absolute rotation can be ascertained by the centrifugal endeavor of the water to rise up the sides of the bucket, as Newton says. But since no empirical signatures are forthcoming in the other arguments from properties, causes and effects, they are typically written off as sadly ineffectual, as though Newton were simply babbling. What's at stake in these passages, though, is what is and what is not a viable definition of true motion.

Acknowlegements. Some of the drafting of this paper was done while a Visiting Scholar at the Max Planck Institut für Wissenschaftsgeschichte. Thanks to George Smith for providing a transcription and translation of Liber Secundus (Add. 3990) done with Anne Whitman and hopefully to appear in print. Thanks to George also for engaging correspondence touching primarily on matters in the penultimate section of this paper. I am also deeply indebted to Marius Stan for much assistance and encouragement.

\section{REFERENCES}

[1] Charles Adam and Paul Tannery, editors. Oevres de Descartes, volume 11. Lèopold Cerf, Paris, 1909. [2] Antoine Arnauld and Pierre Nicole. La Logique ou l'art de penser. Jean de Launey, Paris, 1662.

\footnotetext{
${ }^{36}$ Despite its many virtues, (Stein 1967) also fails to distinguish the purpose of the bucket from that of the globes. Stein sees the Scholium as a whole in epistemic terms. "Newton's analysis of the notions of space and time is ... a classic case of the analysis of the empirical content of a set of theoretical notions" (197).
} 
[3] Antoine Arnauld and Pierre Nicole. Logica, sive ars cogitandi. Andrew Clark, London, 1674.

[4] Antoine Arnauld and Pierre Nicole. Logic; or, the Art of Thinking. London, 1685.

[5] Richard Arthur. Space and relativity in Newton and Leibniz. The British Journal for the Philosophy of Science, 45(1):219-240, 1994.

[6] Isaac Barrow. Lectiones geometricae. London, 1670. Translated into English as Geometrical Lectures (London, 1735). This edition, according to the title page, is "by Edmund Stone" suggesting that Stone is the translator. But the title page also states "Translated from the Latin Edition, revised, corrected and amended by the late Sir Isaac Newton.".

[7] Craig B. Brush, editor. The Selected Works of Pierre Gassendi. Johnson Reprint Corporation, New York and London, 1972.

[8] Walter Charleton. Physiologia Epicuro-Gassendo-Charltoniana. Thomas Newcomb, London, 1654.

[9] I. B. Cohen. Franklin and Newton. The American Philosophical Society, Philadelphia, 1956. Republished in 1966 by Harvard University Press.

[10] I. B. Cohen. Hypotheses in Newton's philosophy. Physis, Rivista Internazionale di Storia della Scienza, 8:163-184, 1966. Reprinted in Proceedings of the Boston Colloquium for the Philosophy of Science 1966/1968, ed. Robert S. Cohen and Marx Wartofsky, Boston Studies in the Philosophy of Science, vol. 5 (Dordrecht: D. Reidel Publishing Co., 1969), pp. 304-326.

[11] René Descartes. Principia philosophiae. Elsevier, Amsterdam, 1644.

[12] René Descartes. Opera philosophica. 2nd edition, 1650.

[13] Robert DiSalle. Newton's philosophical analysis of space and time. In I. Bernard Cohen and George E. Smith, editors, The Cambridge Companion to Newton, pages 33-56. Cambridge University Press, Cambridge, 2002.

[14] René Dugas. Mechanics in the Seventeenth Century. Griffon, Neuchatel, 1958. Translated by Freda Jacquot.

[15] Galileo Galilei. Dialogo sopra i due massimi sistemi del mondo tolemaico e copernicano. Giovanni Batista Landini, Florence, 1632.

[16] Galileo Galilei. Dialogue Concerning the Two Chief World Systems, Ptolemaic 8 Copernican. University of California Press, Berkeley, 2nd edition, 1967 [1632]. Translated by Stillman Drake.

[17] Daniel Garber. Descartes' Metaphysical Physics. University of Chicago Press, Chicago, 1992.

[18] Pierre Gassendi. De motu impresso a motore translato. Louis de Heuqueville, Paris, 1642.

[19] Pierre Gassendi. Animadversiones in decimum librum Diogenis Laertii. Guillaume Barbier, Lyon, 1649.

[20] Pierre Gassendi. Syntagma philosophicum. Laurent Anisson and Jean Baptiste Devenet, Lyon, 1658. Volume 1 of Opera Omnia.

[21] Geoffrey Gorham. Descartes on time and duration. Early Science and Medicine, 12:28-54, 2007.

[22] Geoffrey Gorham. Descartes on god's relation totime. Religious Studies, 44:413-431, 2008.

[23] Anil Gupta. Definitions. In Edward N. Zalta, editor, The Stanford Encyclopedia of Philosophy. Stanford University, summer 2015 edition, 2015. URL = $<$ http://plato.stanford.edu/archives/sum2015/entries/definitions/>.

[24] A. Rupert Hall and Marie Boas Hall, editors. Unpublished scientific papers of Isaac Newton. Cambridge University Press, Cambridge, 1962.

[25] William Harper. Isaac Newton's Scientific Method: Turning Data into Evidence about Gravity and Cosmology. Oxford University Press, Oxford, 2011.

[26] John Harrison. The Library of Isaac Newton. Cambridge University Press, Cambridge, 1978.

[27] John Herivel. The Background to Newton's Principia: A Study of Newton's Dynamical Researches in the Years 1664-84. Oxford University Press, Oxford, 1965.

[28] Christiaan Huygens. Horologium Oscillatorium. F. Muguet, Paris, 1673.

[29] Dana Jalobeanu. Space, bodies and geometry: Some sources of Newton's metaphysics. Zeitsprünge, Forschungen zur Frühen Neuzeit, 11:81-112, 2007.

[30] Andrew Janiak, editor. Isaac Newton: Philosophical Writings. Cambridge University Press, Cambridge, 2014 . 
[31] Johannes Kepler. Astronomia Nova. Heidelberg, 1609.

[32] J. E. McGuire and Martin Tamny. Certain Philosophical Questions: Newton's Trinity Notebook. Cambridge University Press, Cambridge and New York, 1983.

[33] Isaac Newton. Philosophiae Naturalis Principia Mathematica. Joseph Streater, London, 1st edition, 1687.

[34] Isaac Newton. Philosophiae Naturalis Principia Mathematica. Cambridge, 2nd edition, 1713.

[35] Isaac Newton. Opticks. W. and J. Innys, London, 1718.

[36] Isaac Newton. Philosophiae Naturalis Principia Mathematica. London, 3rd edition, 1726.

[37] Isaac Newton. De Mundi Systemate. J. Tonson, J. Osborn and T. Longman, London, 1728.

[38] Isaac Newton. A Treatise on the System of the World. London, 2nd edition, 1731. Reprinted with an introduction by I. B. Cohen by Dawsons of Pall Mall, London, 1969.

[39] Isaac Newton. Über die Gravitation. V. Klostermann, Frankfurt am Main, 1988. Translated by Gernot Böhme.

[40] Isaac Newton. The Principia: Mathematical Principles of Natural Philosophy. University of California Press, 3rd edition, 1999. Translated by I. B. Cohen and Anne Whitman.

[41] Henricus Regius. Fundamenta Physices. Louis Elsevier, Amsterdam, 1646.

[42] Jacques Rohault. Traité de physique. Denis Thierry, Paris, 1671.

[43] Robert Rynasiewicz. By their properties, causes and effects: Newton's scholium on time, space, place and motion - i. The text. Studies in History and Philosophy of Science, 26(1):133-153, 1995.

[44] Robert Rynasiewicz. By their properties, causes and effects: Newton's scholium on time, space, place and motion - ii. The context. Studies in History and Philosophy of Science, 26(2):295-321, 1995.

[45] Robert Rynasiewicz. Newton's views on space, time, and motion. In Edward N. Zalta, editor, Standford Encyclopedia of Philosophy. Stanford University, summer 2014 edition, 2014. URL = $<$ http://plato.stanford.edu/archives/sum2014/entries/newton-stm/>.

[46] Robert Sanderson. Logicae artis compendium. Johannes Lichfield, Oxford, 1631.

[47] Eric Schliesser. Newton's philosophy of time. In Heather Dyke and Adrian Bardon, editors, A Companion to the Philosophy of Time. John Wiley \& Sons, Inc., first edition, 2013.

[48] Marco Sgarbi. The Aristotleian Tradition and the Rise of British Empiricism. Springer, Dordrecht, 2013.

[49] Howard Stein. Newtonian space-time. Texas Quarterly, 10:174-200, 1967. Reprinted in Robert Palter (ed.), The Annus Mirabilis of Sir Isaac Newton, 258-284. Cambridge, Mass.: MIT Press, 1970.

[50] Rebecca Lloyd Waller. Descartes' Temporal Dualism. Lexington Books, Lanham, MD, 2014.

[51] Richard S. Westfall. Force in Newton's Physics. Macdonald and Co., London, 1971.

[52] D. T. Whiteside, editor. The preliminary manuscripts for Isaac Newton's 1687 Principia, 1684-1685. Cambridge University Press, Cambridge, 1989.

[53] Vincent Wing. Harmonicon Coeleste. Robert Leybourn, London, 1651. 